\title{
HOW CULTURE AND MOTIVATION INTERACT IN AN INTERNATIONAL VIRTUAL PROJECT TEAM
}

\author{
Iulia DUMITRAŞCU, Dănuţ Dumitru DUMITRAŞCU \\ "Lucian Blaga" University, Sibiu, Romania \\ iulia.dumitrascu@ulbsibiu.ro, dan.dumitrascu@ulbsibiu.ro
}

\begin{abstract}
Globalization had a significant impact on project management, especially on its structure and the working environment of project teams, because of the increased connectivity due to technology innovations, offering the international project managers the possibility to access high quality human resources across country frontiers, at reduced prices. Internet communication transformed traditional teams in virtual teams, which activity is based on the electronic collaboration tools. The high diversity degree characteristic to virtual teams, from culture to technical tools, can be overwhelming for the international project manager which has to lead its virtual team to success. One of the key processes which lead to a high effective team is the team building process, based on motivation and trust. Even if this seems similar to traditional teams, the path of achieving them is very different and it involves more variables and one of them is the national culture, which we consider one of the most important. This article aims to highlight the importance of understanding each dimension of the national culture so that international managers choose to establish the motivational practices and tools accordingly. We also proposed the profile of the national culture most suitable to work in a virtual environment.
\end{abstract}

Keywords: motivation, culture, international virtual teams, project management.

\section{Introduction}

Organizations around the world are involving in projects developed across borders, building virtual teams, given the many advantages they offer. Virtual teams are increasingly common because global markets require them, and cost-effective technologies now make them practical. Any serious manager needs to know now how to manage them effectively [4]. The diversity characteristic of these teams is determined, primarily, by multiculturalism, so understanding the cultures that interacts with and the differences between them, is a challenge for the managers of international projects, which has to be managed effectively in order to avoid conflicts and to involve virtual teams members in achieving the objectives and scope of the international project. Cross-cultural gaps that are typical of an international project environment introduce further leadership challenges and additional risk [5]. Organizations that do not use virtual teams effectively may be fighting an uphill battle in a global, competitive, and rapidly changing environment [1].

Geert Hofstede developed one of the most comprehensive studies about how the values in the workplace are influenced by national culture. He defines culture as collective programming of the mind, through which members of a group or category of persons are distinguished from others [8]. Through the study he conducted, has established that the values that 
diferentiate countries from another, can be grouped into four dimensions: power distance - measures the extent to which the less powerful memebrs of society accept that power is distribuited unequally; individualism vs collectivism - society position in this dimension is reflected in the members self-image, which can be defined in terms of "I" or "We"; masculinity vs femininity - a society defined as masculine is more competitive, and one with a high degree of femininity is geared more towards cooperation; uncertainty avoidance - the degree to which members of society feel threatened by the unknown. As a result of further research conducted by Michael Harris Bond, supported by Hofstede in 1991, it was added the fifth dimension, namely, long-term oriented - societies with high degree of this dimension are considered more pragmatic, encouraging efforts oriented to modern education as a way to prepare for the future [8]. And in 2010, as a result of the study conducted by Michael Minkov, was added the sixth dimension, indulgence vs. restraint indulgence society allows satisfying relatively free the basic needs of a human being, related to joy to live; instead, a restraint society is the one that supresses needs and regulates them by strict social rules [7].

The model of six national culture dimensions, by which is explained the cultural diversity, is one of the most important ways through which managers can understand cultural differences and can adapt their approach on the construction of the international virtual project team and thus procedures and motivation tools, so these processes to be more efficient. Throughout this paper, we analyze each cultural dimension, in part, and will propose appropriate motivation strategies.

\section{What is the motivation for work in a virtual environment?}

The importance of motivation is given by the following equation proposed by "Victor Vroom's former mentor, N. R. F. Maier, more than a half century ago: job performance $=$ ability $\times$ motivation. This equation succinctly explains why the subject of motivation is a cornerstone in the fields of human resource management, industrial and organization psychology, and organization behavior [12]. By this equation we can understand that the manager of international project, in order to build an efficient virtual team, is not limited to identifying team members' skills, required in the virtual environment, but also to determinate them to use those skills in an effective way, and to mobilize them to continuous improvement.

The concept of work motivation in the virtual environment can be defined in the same manner as in traditional teams. What changes is represented by the factors that determine motivation, and how to use the tools of motivation. Factors driving motivation are dynamic and involve changes both in individuals and the work environment in which they operate. Kanfer Ruth defines work motivation as the set of processes that determine a person's intentions to allocate personal resources across a range of possible actions [11]. According to this definition, the team member controls the way he acts in terms of job tasks and motivation will influence the way to communicate, coordinate and cooperate within the team. Also, motivation varies within and across individuals, and across situations for the same individual [11]. In these circumstances, we can deduce that work motivation in the virtual environment will be determined by the traits of each individual, so that virtual team members to work efficiently should show a strong desire to have more flexibility in setting work schedule, to work from home without the need to physically interact with other team members, desire for independence, without the need to exert control over the individuals, but on processes, and to have self-motivation ability. 
In the literature review, we found as components of motivation, three behavioural dimensions: attention (direction), effort, and persistence [11]. Latham Gary considers "choice, effort, and persistence - the three pillars that define motivation in the workplace [12]. Attention (direction or choice), refers to the actions to which individuals channel their energy. The effort involves the amount of resources that the individual allocates to certain tasks, and persistence is the ability to support longterm effort and attention [11].

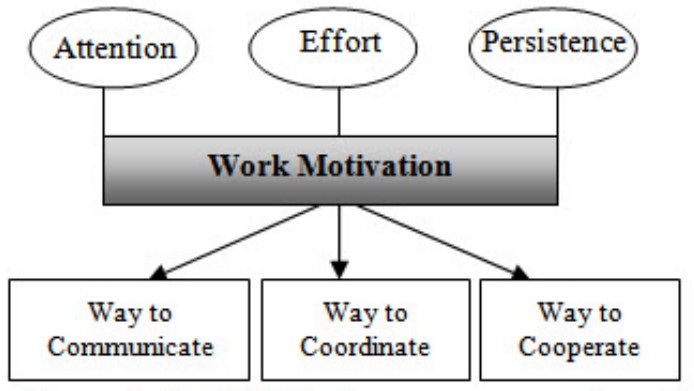

Figure 1: Work Motivation - components and impact. Source: Authors

In the next section, our aim is to highlight how national cultural dimensions affect the three components of work motivation.

\section{How is national culture influencing motivation for work in a virtual environment?}

Globalization has brought with it mass movement of workers and unprecedented cross mingling of persons from different cultures [3]. However, cultural aspects are often overlooked or receive inadequate consideration. Cultures have differing expectations of leaders, different rules about business relationships, and differing rule sets around ways of work [5]. Thus, "human resources policies, motivational strategies and performance reviews need to be adapted for various cultural groups represented among the team [13]. International virtual teams are becoming increasingly heterogeneous in terms of national culture, as the degree of geographic dispersion of team members is higher. To create motivation strategies adapted to national cultures, international project managers must acquire and develop their cultural intelligence. "Cultural intelligence is the capability to function effectively in intercultural contexts, including different national, ethnic, organizational, generational and many other contexts. $90 \%$ of leading executives from sixty-eight countries identified crosscultural leadership as the top management challenge for the next century [13]. Understanding how cultural dimensions influence motivation components, represents a first step in creating effective motivation strategies and tools, which we could name "national culture oriented strategies". Research indicates that highly significant performance increases are possible when motivational strategies are implemented [18].

\subsection{Power distance}

Hofstede states that power distance is the degree of power that managers impose to their subordinates [8].

Considering the studies found in the literature [6], [10], [15], [16] we appreciate that high distance power cultures, team members have no spirit of initiative and they are unwilling to participate in decision making. So we can call their attitude as submissive, oriented to tasks imposed by the manager. They feel safe when they act following strict rules and procedures. At the same time, their efforts will be focused strictly on their duties; any deviation from the job description could mean a demotivation reason. In terms of persistence, as long as team members will perceive a high power degree imposed by their manager, they will feel motivated to fulfil the tasks set. Instead, when members come from a national culture with a low power distance, they will be motivated by their involvement in decision making, having an attitude characterized by being proactively, creative, able to express their opinions and ask for help without fear of managers. In terms of effort, they will focus on achieving the targets, taking into 
account their right to rest, leisure time and holidays. The persistence of effort and attention will be maintained as long as they will feel involved in achieving the company's goals, the manager will not exercise excessive control over them, more equally power distribution and the rewards should be fair and consistent with the performances achieved.

\subsection{Individualism vs. collectivism}

Hofstede's description

of

individualism versus collectivism also refers to the manner in which individuals feel that they belong to a group. High individualism corresponds to the individualistic work [8]. Collectivist mentality sets a precedent where everyone takes responsibility for fellow members of their group, but these groups are clearly defined within the hierarchy [17].

Thus, we believe that this cultural dimension will influence work motivation thereby: 1. Collectivist cultures will turn their attention to carrying out team tasks and their effort is channelled to team goals; attention and effort will be maintained as long as they feel that they are a part of a group and cognitive and emotional comfort will persist, resulting from the fact that they can rely on other team members; 2. Individualistic cultures are oriented towards fulfilment of individual tasks (due to their traits of self-sufficiency and selfmotivation), and the effort is focused on objectives that bring satisfaction. Attention and effort will be maintained as long as the tasks will include new challenges, there are real advancement opportunities and personal merits will be recognized and rewarded.

\subsection{Masculinity vs. Femininity}

According to Hofstede, in this case, the fundamental issue is what motivates people, wanting to be the best (Masculine) or liking what you do (Feminine) [8].

Given these aspects, we believe that this cultural dimension affects the three work motivation components, as follows: 1 . In the masculine cultures, attention is directed to competitive activities, which involve substantial material rewards. The effort focuses on tasks fulfilment in an efficient way and as close to perfection, so as to ensure their success. Persistence in tasks is based on extrinsic motivation, which implies a short period of time, so the team manager must provide these members a variable reward system in addition to the fixed one, and a well-structured career advancement plan; 2. Regarding feminine cultures, attention is geared towards flexible activities, allowing a balance between the time dedicated to the professional functions and the one dedicated to family. The effort focuses on tasks they consider interesting and enjoy their activity, developing friendly relations with other team members, being willing to help them. Attention and effort will be maintained as long as the team manager promotes an egalitarian environment, and offer these members the opportunity to choose for a work program customized to their needs.

\subsection{Uncertainty avoidance}

Sorrentino Richard explains that uncertainty oriented (UO) are high in the desire to attain clarity, but low in the desire to maintain clarity. Their preferred method of handling uncertainty is to seek information and engage in activities that will directly resolve the uncertainty. Such people can be described as having a strong "need to know." In contrast, Certainty Oriented (CO) are low in the desire to attain clarity but are high in the desire to maintain clarity [17].

We believe that this cultural dimension would influence work motivation as follows: 1. In uncertainty oriented cultures, attention is directed to those activities involving freedom of action, creativity and diversity. The effort focuses on satisfying the desire for knowledge, discovery and innovation. Attention and effort will be maintained as long as the team manager will promote a positive informal work environment and involve these members in activities which arouse 
their curiosity and stimulate their creative ability; 2. In certainty oriented cultures, attention will be directed towards activities with high safety degree and foresight. The effort will be focused on maintaining certain situations, using strict rules, policies, group norms, or to call for expert help. Persistence in tasks fulfilment is based on the existence of an environment free of unpredictable situations and changes. Such situations would create tension, stress and poor performance.

\subsection{Long term orientation vs. Short term normative orientation}

This dimension describes how every society has to maintain some links with its own past while dealing with the challenges of the present and future, and societies prioritise these two existential goals differently [8].

Regarding the impact on work motivation, we consider that in long oriented cultures, attention is directed towards innovative activities with long-term impact, and effort is concentrated on actions regarding personal and professional development, based on a well structured career plan. This cultural dimension is also characterized by a high degree of tenacity. Instead, in short-term oriented cultures, attention is geared towards activities which do not involve major changes; the effort is focused on actions that provide immediate results and rewards. This cultural dimension is characterized by a lack of ability to sustain long term effort and attention.

\subsection{Indulgence vs. Restraint}

One challenge that confronts humanity, now and in the past, is the degree to which small children are socialized. Without socialization we do not become extent to which people try to control their desires and impulses, based on the way they were raised [8].

Regarding the impact on work motivation, we consider that for indulgent cultures, attention will be oriented towards activities that allow freedom of opinion and expression, which take place in a positive and relaxed environment, promoting networking between team members. Effort will be focused on enjoyable actions that ensure personal and professional satisfaction. Attention and effort can be maintained on a long term, as long as leisure activities dedicated to relaxation and socializing will be respected. In retained cultures, attention will be oriented to routine activities that do not involve a high degree of socialization and do not require expressing opinions. The effort will be focused on actions that involve tangible rewards. The degree of persistence is low, motivation being mainly extrinsic, relying on quick results quantified in money.

\section{Which are the most suitable cultural dimensions to work effectively in a virtual environment?}

Many virtual team managers, do not take into account, the national cultural differences, before building the virtual team, leading, over time, to conflicts and poor team performance [9]. For virtual teams to succeed, the organization's leadership must establish a culture that values teamwork, communication, learning, outcome-based performance, and capitalizing on diversity [1]. As a result of bibliographic research carried out on national cultural dimensions and the international virtual team characteristics [2], we propose a national cultural profile which best adapts to activities developed in a virtual environment. 

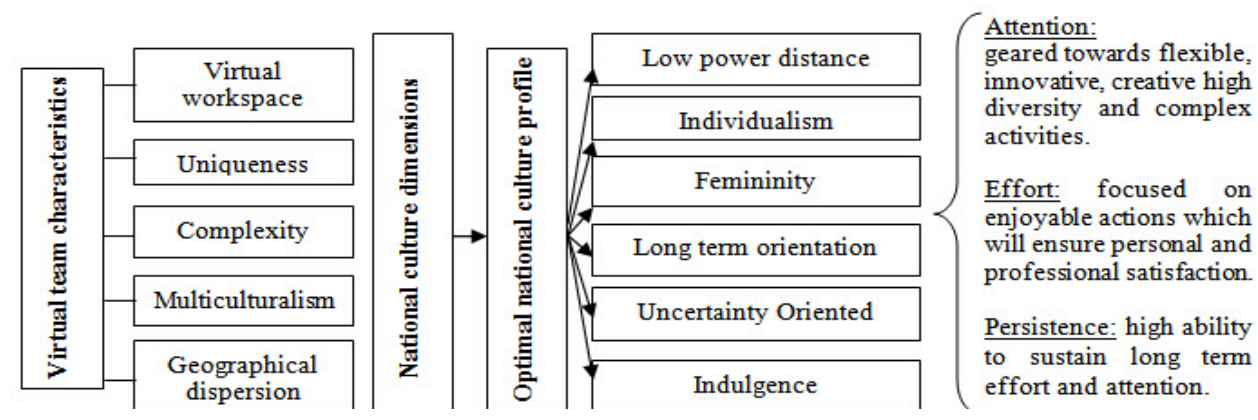

Figure 2: Optimal national culture profile for a virtual workplace. Source: Authors

\section{Conclusions}

The cultural dimensions of Hofstede represent a very good tool that can provide a forecast on the team members personality traits and the differences between them, so this article can be useful to managers of international projects, as well as virtual organizations, for the department staff of human resources, working in a virtual and multicultural environment, in order to establish effective motivation strategies and tools.

This paper brings a novelty element, given that the impact of national culture on the three dimensions of work motivation has not been addressed so far in the literature, in this approach. Other contributions that this article brings are given by the two representative schemes: Figure 1 - Work Motivation - components and impact. Figure 2 - Optimal national culture profile for a virtual workplace.

Also, this paper is the start point for conducting an empirical research to validate the national cultural dimensions that best adapts to international virtual working environment and to identify the most appropriate instruments for motivation.

\section{References}

[1] Duarte L. Deborah, Mastering virtual teams: strategies, tools, and techniques that succeed, Jossey-Bass; 3 edition (April 21, 2006).

[2] Dumitraşcu Iulia, Dumitraşcu Dănuţ Dumitru, Creating Effective International Project Team, 2016, unpublished.

[3] Erez Miriam, Kleinbeck Uwe, Thierry Henk, Work Motivation in the Context of a Globalizing Economy, Psychology Press; $1^{\text {st }}$ edition, 2001.

[4] Fisher Kimball, Fisher Mareen, Manager's guide to Virtual Teams, McGraw-Hill Education, $1^{\text {st }}$ edition, 2011.

[5] Friedman Sue, Katz Lothar, Cristical Success Factorsfor International Projects, available at http://www.managingprojectsacrossborders.com/, accessed on 1st February 2016.

[6] Helou Sabine, Viitala Timo, How culture and motivation interract? a cross-cultural study, 2007, available at http://www.diva-portal.org, accessed on $16^{\text {th }}$ of March 2016.

[7] Hofstede Geert, Hofstede Gert Jan, Minkov Michael, 2010, Cultures and Organizations: Software of the Mind. Revised and Expanded 3rd Edition. New York: McGraw-Hill USA.

[8] Hofstede Geert, 2001, Culture's Consequences: Comparing Values, Behaviors, Institutions, and Organizations Across Nations. Second Edition, Thousand Oaks CA: Sage Publications.

[9] Jones Nory B., Graham C. Matt, Virtual Teams in Business and Distance Education: Reflections from an MBA Class, Journal of Business\& Economic Policy, vol. 2, $\mathrm{n}^{\mathrm{o}} 1$, 2015, available at http://jbepnet.com, accessed on $18^{\text {th }}$ of January 2016. 
[10] Khatri Neresh, Consequences of Power Distance Orientation in Organisations, The Journal of Business Perspective January 2009 13: 1-9, available at http://vis.sagepub.com, accessed on $15^{\text {th }}$ of February 2016.

[11] Kanfer Ruth, Chen Gilad, Work Motivation: Past, Present and Future, Routledge; $1^{\text {st }}$ edition, 2008.

[12] Latham P. Gary, Work Motivation: History, Theory, Research, and Practice, SAGE Publications, Inc; $2^{\text {nd }}$ edition, 2011.

[13] Livermore David, Leading with Cultural Intelligence: The Real Secret to Success, AMACOM, Second Edition edition, 2015.

[14] Lothar Katz, Freedman Sue, Managing projects across borders, 2008, available at http://www.globalprojectmanagement.org, accessed on $8^{\text {th }}$ of February 2016.

[15] Rau Pei-Luen Patrick, Liu Jun, Juzek Christian, Nowacki Christoph Reiner, Fostering Job Satisfaction and Motivation through Power Distance: A study of German Expatriates Leadership in China, Global Business and Management Research: An International Journal Vol. 5, No. 4 (2013), available at http://www.gbmr.ioksp.com, accessed on 15th of March 2016.

[16] Saadat Din Muhammad, Mohsin Bashir, Khaliq Ur Rehman Cheema, Sehrish Saba Zafar, The Role of Power Distance in the Relationship between Employee Motivation and Organizational Commitment: A Study on Education Sector of Pakistan, IOSR Journal of Business and Management (IOSR-JBM) e-ISSN: 2278-487X, p-ISSN: 23197668. Volume 16, Issue 1. Ver. III (Jan. 2014), PP 09-18, vailable at www.iosrjournals.org, accessed on $18^{\text {th }}$ of January 2016.

[17] Sorrentino Richard, Yamaguchi Susumu, Handbook of motivation and cognition across cultures, Academic Press; $1^{\text {st }}$ edition, 2008.

[18] Wlodaraczyk Z. Andrej, Work Motivation. A systemic framework for a multilevel strategy, $1^{\text {st }}$ edition, AuthorHouse, 2011.

[19] Wood, Michael, 2014, Virtual Teams: Do the Challenges Outweigh the Benefits?,

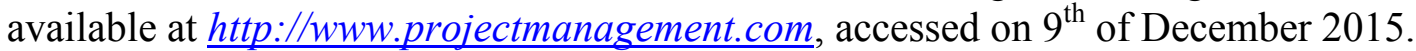

